\author{
Marquette University \\ e-Publications@Marquette
}

10-13-2001

\title{
Structural Evidence That the Methionyl Aminopeptidase from Escherichia coli Is a Mononuclear Metalloprotease
}

\author{
Nathaniel J. Cosper \\ University of Georgia \\ Ventris M. D'Souza \\ Utah State University \\ Robert A. Scott \\ University of Georgia
}

Richard C. Holz

Marquette University, richard.holz@marquette.edu

Follow this and additional works at: https://epublications.marquette.edu/chem_fac

Part of the Chemistry Commons

\section{Recommended Citation}

Cosper, Nathaniel J.; D'Souza, Ventris M.; Scott, Robert A.; and Holz, Richard C., "Structural Evidence That the Methionyl Aminopeptidase from Escherichia coli Is a Mononuclear Metalloprotease" (2001).

Chemistry Faculty Research and Publications. 306.

https://epublications.marquette.edu/chem_fac/306 
Marquette University

e-Publications@Marquette

\title{
Chemistry Faculty Research and Publications/College of Arts and Sciences
}

This paper is NOT THE PUBLISHED VERSION; but the author's final, peer-reviewed manuscript. The published version may be accessed by following the link in the citation below.

Biochemistry, Vol. 40, No. 44 (October 13, 2001): 13302-13309. DOI. This article is @ American Chemical Society Publications and permission has been granted for this version to appear in $\underline{\mathrm{e}}-$ Publications@Marquette. American Chemical Society Publications does not grant permission for this article to be further copied/distributed or hosted elsewhere without the express permission from American Chemical Society Publications.

\section{Structural Evidence That the Methionyl Aminopeptidase from Escherichia coli Is a Mononuclear Metalloprotease}

\author{
Nathaniel J. Cosper \\ Department of Chemistry, University of Georgia, Athens, Georgia \\ Ventris M. D'souza \\ Department of Chemistry and Biochemistry, Utah State University, Logan, Utah \\ Robert A. Scott \\ Department of Chemistry, University of Georgia, Athens, Georgia \\ Richard C. Holz \\ Department of Chemistry and Biochemistry, Utah State University, Logan, Utah
}




\section{SUBJECTS:}

Peptides and proteins, Metals, Monomers, lons

\section{Abstract}

The Co and Fe K-edge extended X-ray absorption fine structure (EXAFS) spectra of the methionyl aminopeptidase from Escherichia coli (ECMetAP) have been recorded in the presence of 1 and 2 equiv of either $\mathrm{Co}(\mathrm{II})$ or Fe(II) (i.e., [Co(II)_(EcMetAP)], [Co(II)Co(II)(EcMetAP)], [Fe(II)_(EcMetAP)], and [Fe(II)Fe(II)(EcMetAP)]). The Fourier transformed data of both [Co(II)_(EcMetAP)] and [Co(II)Co(II)(EcMetAP)] are dominated by a peak at ca. $2.05 \AA$, which can be fit assuming 5 light atom $(\mathrm{N}, \mathrm{O})$ scatterers at $2.04 \AA$. Attempts to include a Co-Co interaction (in the 2.4-4.0 $\AA$ range) in the curve-fitting parameters were unsuccessful. Inclusion of multiplescattering contributions from the outer-shell atoms of a histidine-imidazole ring resulted in reasonable Debye-Waller factors for these contributions and a slight reduction in the goodness-of-fit value $\left(f^{\prime}\right)$. These data suggest that a dinuclear $\mathrm{Co}(\mathrm{II})$ center does not exist in EcMetAP and that the first Co atom is located in the histidine-ligated side of the active site. The EXAFS data obtained for [Fe(II)_(EcMetAP)] and [Fe(II)Fe(II)(EcMetAP)] indicate that Fe(II) binds to EcMetAP in a similar site to Co(II). Since no X-ray crystallographic data are available for any Fe(II)-substituted EcMetAP enzyme, these data provide the first glimpse at the Fe(II) active site of MetAP enzymes. In addition, the EXAFS data for [Co(II)Co(II)(EcMetAP)] incubated with the antiangiogenesis drug fumagillin are also presented.

Methionyl aminopeptidases (MetAPs) ${ }^{1}$ represent a unique class of proteases that are capable of removing the $\mathrm{N}$ terminal methionine residues from nascent polypeptide chains (1-4). In the cytosol of eukaryotes, proteins are initiated with an $\mathrm{N}$-terminal methionine residue; however, proteins synthesized in prokaryotes, mitochondria, and chloroplasts are initiated with an N-terminal formylmethionyl residue. The formyl group is initially removed by a peptide deformylase before MetAP's remove the N-terminal methionine (2). Removal of N-terminal methionine residues from nearly all newly synthesized peptides, depending on the nature of the penultimate amino acid, is essential for cotranslational and posttranslational modifications that are critical for fully functional enzymes (5), correct cellular localization, and the timely degradation of proteins (1-4). Deletion of the gene encoding MetAP is lethal to Escherichia coli, Salmonella typhimurium, and Saccharomyces cerevisiae; therefore, MetAP's are essential for cell growth and proliferation (6-8). Recently, the type II MetAP from eukaryotes has been identified as the molecular target for the antiangiogenesis drugs ovalicin and fumagillin (9-13). Thus, the inhibition of aminopeptidase activity in malignant tumors is critically important in preventing the growth and proliferation of these types of cells and, for this reason, has become the subject of intense efforts in inhibitor design.

The MetAP's from E. coli, Homo sapiens, and Pyrococcus furiosus have been crystallographically characterized (13-16). These MetAP's and all other MetAP's studied to date have been shown to have identical catalytic domains that contain a bis( $\mu$-carboxylato)( $\mu$-aquo/hydroxo)dicobalt core with an additional carboxylate residue at each metal site and a single histidine residue bound to one of the two metal ions (13-16). Recently, it was suggested that the in vivo metal ion for the MetAP from E. coli (EcMetAP) is Fe(II) on the basis of a combination of whole cell metal analyses and activity measurements as well as in vitro activity measurements and substrate

binding constants $(17,18)$. In addition, the observed catalytic activity as a function of divalent metal ion and the metal binding constants for both Fe(II) and Co(II) EcMetAP led to the proposal that EcMetAP functions as a mononuclear enzyme in vivo (17). The high-affinity or catalytically relevant metal binding site was assigned as the histidine-containing site; however, no structural data exist to verify these kinetic and spectroscopic data. Extended X-ray absorption fine structure (EXAFS) spectroscopy is particularly well suited to clarify structural 
problems of this type $(19,20)$. EXAFS data are sensitive to heavy atom scatterers in the second coordination sphere, providing direct evidence for dinuclear sites, if they exist. Reported herein are Co and Fe K-edge EXAFS data for the catalytically competent $\mathrm{Co}(\mathrm{II})$ - and Fe(II)-loaded EcMetAP and the catalytically inactive Co(III)- and Fe(III)-bound forms of EcMetAP. In addition, EXAFS data of the Co(II)-loaded form of EcMetAP bound by the antiangiogenesis agent fumagillin are presented.

\section{Materials and Methods}

\section{Protein Expression and Purification.}

Recombinant EcMetAP was expressed and purified as previously described from a stock culture kindly provided by Drs. Brian W. Matthews and W. Todd Lowther $(12,18)$. Purified EcMetAP exhibited a single band on SDS-PAGE and a single symmetrical peak in matrix-assisted laser desorption ionization time-of-flight (MALDITOF) mass spectrometric analysis indicating $M_{r}=29630 \pm 10$. Protein concentrations were estimated from the absorbance at $280 \mathrm{~nm}$ using an extinction coefficient of $16500 \mathrm{M}^{-1} \mathrm{~cm}^{-1}(12,18)$. Apo-MetAP samples were exchanged into $25 \mathrm{mM}$ HEPES, pH 7.5, containing $150 \mathrm{mM} \mathrm{KCl}$ (Centricon-10, Millipore Corp.). Apo-MetAP samples were incubated anaerobically with $\mathrm{MCl}_{2}$, where $\mathrm{M}=\mathrm{Co}(\mathrm{II})$ or $\mathrm{Fe}(\mathrm{II})$ for 30 min as previously reported (18).

\section{Enzymatic Assay of EcMetAP.}

EcMetAP was assayed for catalytic activity with Met-Gly-Met-Met as the substrate (8 mM) using an HPLC method described previously (18). This method is based on the spectrophotometric quantitation of the reaction product Gly-Met-Met at $215 \mathrm{~nm}$ following separation on a C8 HPLC column (Phenomenex, Luna; $5 \mu \mathrm{m}, 4.6 \times 25$ $\mathrm{cm}$ ). The kinetic parameter $v$ (velocity) was determined at $\mathrm{pH} 7.5$ by quantifying the tripeptide Gly-Met-Met at $215 \mathrm{~nm}$ in triplicate. Enzyme activities are expressed as units per milligram, where 1 unit is defined as the amount of enzyme that releases $1 \mu \mathrm{mol}$ of Gly-Met-Met at $30^{\circ} \mathrm{C}$ in $1 \mathrm{~min}$. Catalytic activities were determined with an error of $\pm 10 \%$.

\section{X-ray Absorption Spectroscopy.}

EXAFS samples of ECMetAP $(1 \mathrm{mM})$ were frozen in polycarbonate cuvettes, $24 \times 3 \times 1 \mathrm{~mm}$ with a $0.025 \mathrm{~mm}$ Mylar window covering one $24 \times 3 \mathrm{~mm}$ face. XAS data were collected at the Stanford Synchrotron Radiation Laboratory (SSRL) with the SPEAR storage ring operating in a dedicated mode at $3.0 \mathrm{GeV}$ (Table 1). The edge regions for multiple scans obtained on the same sample were compared to ensure that the sample was not damaged by exposure to X-ray radiation. EXAFS analysis was performed using EXAFSPAK software (wwwssrl.slac.stanford.edu/exafspak.html), according to standard procedures (19). Multiple-scattering analysis was performed as described previously (21). Both single- and multiple-scattering paths $\leq 4.5 \AA$ from either the Fe or Co atom were used to identify and quantify imidazole coordination due to histidine. Multiple scattering models, calculated using FEFF v7.02 (22), were based on either bis( $N$ methylimidazole)bis(diphenylborondimethylglyoximato)iron(II) dichloromethane solvate (23) or hexakis(imidazole)cobalt(II) carbonate pentahydrate (24). The model was edited to only the metal atom and one imidazole, and the coordinates were imported into FEFF to calculate scattering amplitudes and phase shifts for each scattering path containing four or fewer legs. A constrained fitting process was then used with the following parameters: Coordination numbers were constrained to be integer or half-integer values (the latter representing a ligand bound to one of the two metal ions); the distances for outer-shell atoms of imidazole rings were constrained to be a constant difference with the inner-shell imidazole atom distance. Only a single $\Delta E_{0}$ value was optimized. Scaling factors were determined from model compound analysis. Debye-Waller values for imidazole $C_{2}, N_{3}, C_{4}$, and $C_{5}$ atoms were constrained to be multiples of one another but were not tied to the first-shell $\left[\mathrm{N}_{1},(\mathrm{~N}, \mathrm{O})\right]$ Debye-Waller values. This allows non-imidazole first-shell ligands to have Debye-Waller 
values independent of the imidazole ligand values. Possible coordination numbers of histidyl imidazole ligands were chosen from fits that yielded chemically and physically reasonable Debye-Waller factors for the outer-shell atoms, since goodness-of-fit values $\left(f^{\prime}\right)$ were relatively insensitive to these coordination numbers.

Table 1: X-ray Absorption Spectroscopic Data Collection

\begin{tabular}{|l|l|l|}
\hline & Co EXAFS & Fe EXAFS \\
\hline SR facility & SSRL & SSRL \\
\hline beamline & $7-3,9-3$ & $7-3,9-3$ \\
\hline current in storage ring, $\mathrm{mA}$ & $50-100$ & $50-100$ \\
\hline monochromator crystal & Si[220] & Si[220] \\
\hline detection method & fluorescence & fluorescence \\
\hline detector type & solid-state array ${ }^{a}$ & solid-state array ${ }^{a}$ \\
\hline scan length, min & 24 & 20 \\
\hline scans in average & 10 & 10 \\
\hline temperature, K & 10 & 10 \\
\hline energy standard & Co foil, first inflection & Fe foil, first inflection \\
\hline energy calibration, eV & 7709.5 & 7111.3 \\
\hline$E_{0}$, eV & 7715 & 7120 \\
\hline preedge background & & \\
\hline energy range, eV & $7390-7670$ & $6789-7075$ \\
\hline Gaussian center, eV & 6930 & 6403 \\
\hline Gaussian width, eV & 750 & 750 \\
\hline spline background & & \\
\hline energy range, eV & $7715-7952(4)$ & $7120-7354(4)$ \\
\hline (polynomial order) & $7952-8189(4)$ & $7354-7589(4)$ \\
\hline & $8189-8427(4)$ & $7589-7822(4)$ \\
\hline
\end{tabular}

a The 13-element Ge solid-state X-ray fluorescence detector at SSRL is provided by the NIH Biotechnology Research Resource.

\section{Results and Discussion}

Cobalt and iron K-edge X-ray absorption (XAS) spectra were acquired on $1 \mathrm{mM}$ samples of EcMetAP with 1 or 2 equiv of added Co(II) (i.e., [Co(II)_(EcMetAP)] and [Co(II)Co(II)(EcMetAP)], respectively) or 1 or 2 equiv of added $\mathrm{Fe}(\mathrm{II})$ (i.e., [Fe(II)_(EcMetAP)] and [Fe(II)Fe(II)(EcMetAP)], respectively), as well as for the fully loaded Co(III) and $\mathrm{Fe}(\mathrm{III})$ forms of the protein and for [Co(II)Co(II)(EcMetAP)] incubated with the inhibitor fumagillin. For fully loaded samples (e.g., [Co(II)Co(II)(EcMetAP)]), the EXAFS data reveal an average of both metal ion environments. The $1 \mathrm{~s} \rightarrow 3 \mathrm{~d}$ preedge transitions for [Co(II)_(EcMetAP)] and [Co(II)Co(II)(EcMetAP)] occur at $7709 \mathrm{eV}$ with a peak intensity of 0.118 and $0.127 \mathrm{eV}$, respectively (Figure 1a). Since $1 \mathrm{~s} \rightarrow 3 \mathrm{~d}$ preedge transitions are Laporte forbidden in centrosymmetric environments (e.g., octahedral but not tetrahedral), the intensity of the $1 \mathrm{~s} \rightarrow 3 \mathrm{~d}$ preedge transitions is inversely proportional to coordination number (assuming tetrahedral four-coordination). The intensities of the observed transitions for [Co(II)_(EcMetAP)] and [Co(II)Co(II)(EcMetAP)] are consistent with, on average, five- or six-coordinate $\operatorname{Co}(I I)$ sites $(25,26)$. 

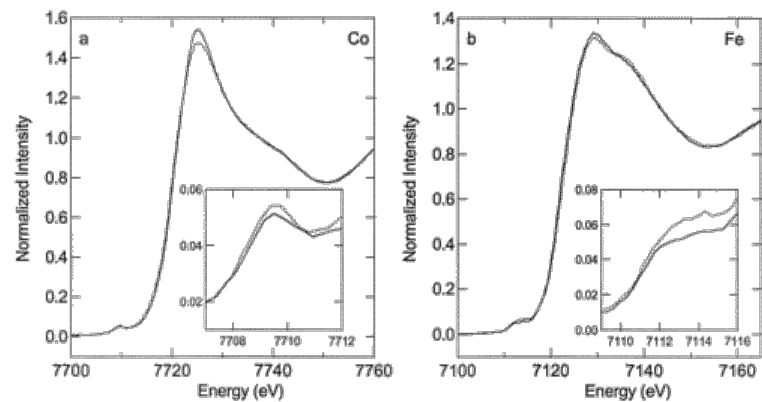

Figure 1 X-ray absorption K-edge spectra for EcMetAP: (a) [Co(II)Co(II)(EcMetAP)] (solid) and [Co(II)_(EcMetAP)] (dotted); (b) [Fe(II)Fe(II)(EcMetAP)] (solid) and [Fe(II)_(EcMetAP)] (dotted). In the inset, the preedge 1s $\rightarrow 3 d$ transition is expanded.

Fourier transforms (FTs) of the EXAFS data for both [Co(II)_(EcMetAP)] and [Co(II)Co(II)(EcMetAP)] are dominated by a peak at ca. $2.05 \AA$ (Figure 2). Excellent single-shell fits of EXAFS spectra for both [Co(II)_(EcMetAP)] and [Co(II)Co(II)(EcMetAP)] were obtained with $6 \pm 1$ N/O scatterers at 2.04 $\AA$ (fits 2-4 and 8-10; Table 2). Attempts to include a Co-Co interaction (in the 2.4-4.0 $\AA$ range) in the curve-fitting parameters were unsuccessful. Inclusion of multiple-scattering contributions from the outer-shell atoms of a histidine-imidazole ring results in reasonable Debye-Waller factors for these contributions and a slight reduction in the goodness-of-fit value $\left(f^{\prime}\right)$ (fits 5 and 11 ; Table 2 ). This is consistent with the suggestion of a single histidine ligand from the crystallographic analyses (13-16). The Debye-Waller factor values are higher for [Co(II)Co(II)(EcMetAP)] than for [Co(II)_(ECMetAP)], suggesting that the first Co atom is located in the histidineligated site.
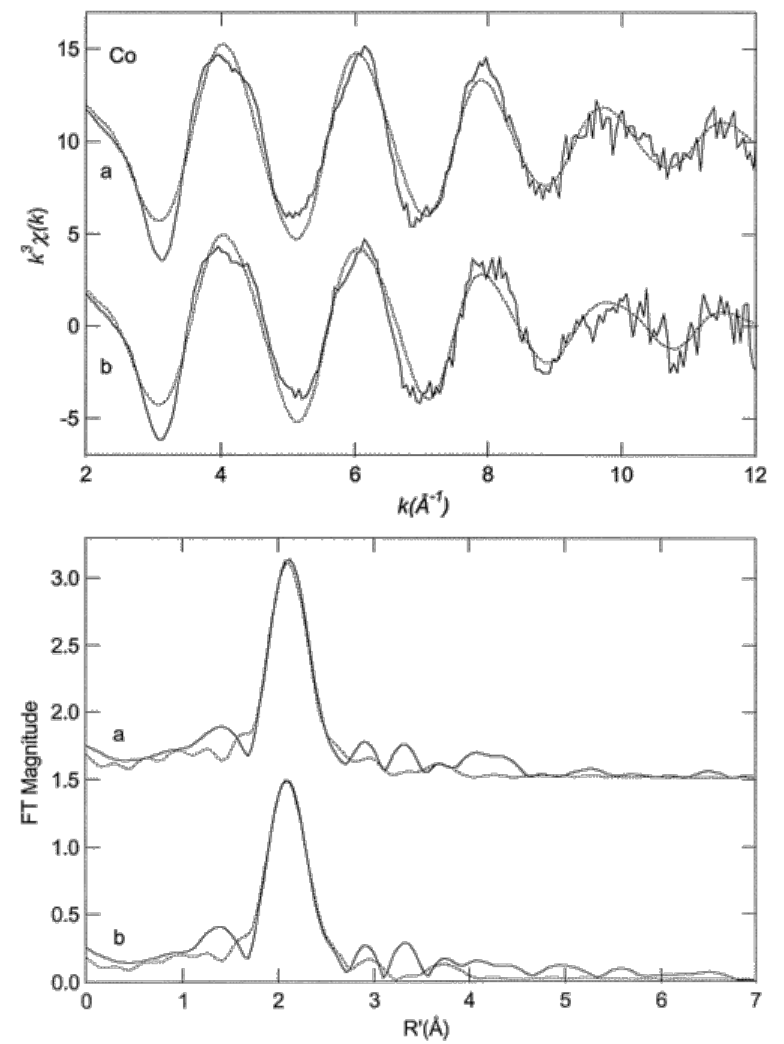

Figure $2 k^{3}$-weighted Co EXAFS (top) and Fourier transforms (bottom, over $k=2-12 \AA^{-1}$ ) for [Co(II)Co(II)(EcMetAP)] (a; solid) and the calculated spectra for $\mathrm{Co}-(\mathrm{O}, \mathrm{N})_{5}$ (imid) (dotted; fit 11, Table 2) and [Co(II)_(EcMetAP)] (b; solid) and the calculated spectra for $\mathrm{Co}-(\mathrm{O}, \mathrm{N})_{5}(\mathrm{imid})$ (dotted; fit 5, Table 2). 
Table 2: Curve-Fitting Results for Co EcMetAP EXAFS ${ }^{a}$

\begin{tabular}{|c|c|c|c|c|c|c|c|}
\hline & fit & shell & $N_{\mathrm{s}}$ & $R_{\mathrm{as}}(\AA)$ & $\sigma_{\mathrm{as}}{ }^{2}\left(\AA^{2}\right)$ & $\Delta E_{0}(\mathrm{eV})$ & $f^{\prime b}$ \\
\hline [Co(II)_(EcMetAP)], & 1 & $\mathrm{Co}-\mathrm{O}$ & 4 & 2.05 & 0.0060 & -1.17 & 0.094 \\
\hline MC20C, $2-12 \AA^{-1}$ & 2 & $\mathrm{Co}-\mathrm{O}$ & 5 & 2.04 & 0.0078 & -1.28 & 0.084 \\
\hline \multirow[t]{9}{*}{$\Delta k^{3} \chi=10.75$} & 3 & Co-O & 6 & 2.05 & 0.0096 & -1.43 & 0.082 \\
\hline & 4 & $\mathrm{Co}-\mathrm{O}$ & 7 & 2.04 & 0.0114 & -1.57 & 0.084 \\
\hline & 5 & $\mathrm{Co}-(\mathrm{O}, \mathrm{N})$ & 6 & 2.05 & 0.0078 & -1.29 & 0.077 \\
\hline & & $\mathrm{Co}-\mathrm{C}$ & 1 & 2.85 & 0.0041 & & \\
\hline & & $\mathrm{Co}-\mathrm{C}$ & 1 & [2.96] & {$[0.0043]$} & & \\
\hline & & $\mathrm{Co}-\mathrm{C}$ & 1 & [3.93] & [0.0057] & & \\
\hline & & Co-N & 1 & [3.99] & {$[0.0057]$} & & \\
\hline & 6 & $\mathrm{Co}-\mathrm{O}$ & 5 & 2.05 & 0.0078 & -1.25 & 0.083 \\
\hline & & Co-Co & 1 & 3.19 & 0.0140 & & \\
\hline [Co(II)Co(II)(EcMetAP)], & 7 & $\mathrm{Co}-\mathrm{O}$ & 4 & 2.06 & 0.0052 & -0.74 & 0.090 \\
\hline $\mathrm{MC} 22 \mathrm{C}, 2-12 \AA^{-1}$ & 8 & $\mathrm{Co}-\mathrm{O}$ & 5 & 2.05 & 0.0068 & -0.84 & 0.078 \\
\hline \multirow[t]{9}{*}{$\Delta k^{3} \chi=11.42$} & 9 & $\mathrm{Co}-\mathrm{O}$ & 6 & 2.05 & 0.0084 & -1.03 & 0.072 \\
\hline & 10 & $\mathrm{Co}-\mathrm{O}$ & 7 & 2.05 & 0.0103 & -1.21 & 0.073 \\
\hline & 11 & $\mathrm{Co}-(\mathrm{O}, \mathrm{N})$ & 6 & 2.05 & 0.0085 & -0.99 & 0.069 \\
\hline & & $\mathrm{Co}-\mathrm{C}$ & 1 & 2.83 & 0.0063 & & \\
\hline & & $\mathrm{Co}-\mathrm{C}$ & 1 & [2.95] & {$[0.0066]$} & & \\
\hline & & $\mathrm{Co}-\mathrm{C}$ & 1 & [3.90] & {$[0.0087]$} & & \\
\hline & & Co-N & 1 & [3.97] & [0.0088] & & \\
\hline & 12 & $\mathrm{Co}-\mathrm{O}$ & 5 & 2.06 & 0.0068 & -0.83 & 0.077 \\
\hline & & Co-Co & 1 & 3.14 & 0.0250 & & \\
\hline [Co(III)Co(III)(EcMetAP)], & 13 & $\mathrm{Co}-\mathrm{O}$ & 4 & 2.05 & 0.0076 & 0.25 & 0.087 \\
\hline MC33C, $2-12 \AA^{-1}$ & 14 & $\mathrm{Co}-\mathrm{O}$ & 5 & 2.05 & 0.0097 & 0.02 & 0.078 \\
\hline \multirow[t]{9}{*}{$\Delta k^{3} \chi=11.23$} & 15 & Co-O & 6 & 2.04 & 0.0120 & -0.35 & 0.076 \\
\hline & 16 & $\mathrm{Co}-\mathrm{O}$ & 7 & 2.04 & 0.0139 & -0.67 & 0.077 \\
\hline & 17 & $\mathrm{Co}-(\mathrm{O}, \mathrm{N})$ & 5 & 2.05 & 0.0097 & 0.05 & 0.076 \\
\hline & & $\mathrm{Co}-\mathrm{C}$ & 1 & 2.85 & 0.0133 & & \\
\hline & & Co-C & 1 & [2.96] & [0.0138] & & \\
\hline & & $\mathrm{Co}-\mathrm{C}$ & 1 & [3.92] & [0.0183] & & \\
\hline & & Co-N & 1 & [3.99] & {$[0.0187]$} & & \\
\hline & 18 & $\mathrm{Co}-\mathrm{O}$ & 5 & 2.05 & 0.0097 & -0.07 & 0.078 \\
\hline & & Co-Co & 1 & 3.07 & 0.0299 & & \\
\hline
\end{tabular}

${ }^{a}$ Shell is the chemical unit defined for single- and multiple-scattering calculations. $N_{\mathrm{s}}$ is the number of scatterers per shell. $R_{\text {as }}$ is the metal scatterer distance. $\sigma_{\text {as }}{ }^{2}$ is a mean square deviation in $R_{\text {as. }} \Delta E_{0}$ is the shift in $E_{0}$ for the theoretical scattering functions. Numbers in square brackets were constrained to be multiples of the value above. ${ }^{b} f^{\prime}$ is a normalized error (chi-squared): $f^{\prime}=\left\{\sum_{i}\left[k^{3}(-)\right]^{2} / N\right\}^{1 / 2} /\left[\left(k^{3}\right)_{\max }-\left(k^{3}\right)_{\min }\right]$.

The observed EXAFS spectra of Co(II)-loaded EcMetAP suggest that the Co(II) ions reside in a distorted penta- or hexacoordinate geometry, containing a histidine ligand. This is consistent with the X-ray crystal structure of Co(II)-loaded ECMetAP, which indicates that the histidine-ligated Co(II) ion resides in a distorted trigonalbipyramidal coordination environment while the second Co(II) ion is either trigonal bipyramidal or distorted octahedral $(16,27)$. The average bond distances obtained by EXAFS for both EcMetAP samples are in excellent agreement with the crystallographically determined bond lengths for [Co(II)Co(II)(EcMetAP)] of $2.04 \AA$ (16). Additionally, it was recently reported, on the basis of ${ }^{1} \mathrm{H}$ NMR data, that upon the addition of Co(II) to ECMetAP the first $\mathrm{Co}$ (II) bound to the lone histidine residue in the active site (17). The previously reported electronic 
absorption spectrum of EcMetAP upon the addition of 1 equiv of $\mathrm{Co}(\mathrm{II})$ under anaerobic conditions exhibited three resolvable $d-d$ transitions at 580,630 , and $690 \mathrm{~nm}\left(\varepsilon=60,50\right.$, and $20 \mathrm{M}^{-1} \mathrm{~cm}^{-1}$, respectively) (17). These data are also consistent with the first $\mathrm{Co}(\mathrm{II})$ ion residing in a pentacoordinate environment. Similarly, the observed EPR spectrum of [Co(II)_(EcMetAP)] was shown to be a broad, featureless signal, suggesting an unconstrained ligand field (17). Thus, there is a great deal of flexibility in the ligand environment $(28,29)$. Moreover, the low $E / D$ value of 0.09 (in general, $1 / 3 \geq E / D \geq 0$ ) reported for [Co(II)_(EcMetAP)] also indicates a fairly high degree of axial symmetry. The combination of the electronic absorption, EPR, and EXAFS data suggests that the single catalytically competent Co(II) ion in EcMetAP resides in a site that is consistent with the histidine-containing site reported in the X-ray crystal structure of [Co(II)Co(II)(EcMetAP)] (16). Furthermore, the EXAFS data do not detect a Co-Co interation, providing no support for a dinuclear Co(II) site in EcMetAP, as seen in the published X-ray crystal structures for all MetAP's $(15,16)$.

The $1 \mathrm{~s} \rightarrow 3 \mathrm{~d}$ preedge transitions are observed at $7113 \mathrm{eV}$ with intensities of 0.130 and $0.151 \mathrm{eV}$ for [Fe(II)_(EcMetAP)] and [Fe(II)Fe(II)(EcMetAP)], respectively (Figure 1B). The intensities of the 1s $\rightarrow 3 d$ transitions are consistent with $\mathrm{Fe}$ (II) sites that are, on average, five-coordinate (30). These data suggest that Fe(II) binds to EcMetAP in a similar site to Co(II). The Fourier transforms for [Fe(II)_(EcMetAP)] and [Fe(II)Fe(II)(EcMetAP)] (Figure 3, bottom), similar to the Co FTs, are dominated by peaks at ca. $2.03 \AA$. Excellent single-shell fits of this peak in both [Fe(II)_(EcMetAP)] and [Fe(II)Fe(II)(EcMetAP)] were obtained with 5 or 6 N/O scatterers per Fe atom at 2.04 or $2.03 \AA$ (Fits 2, 3, 7, and 8; Table 3). Attempts to include either an Fe-Fe or an Fe-imidazole interaction in the curve-fitting parameters resulted in fits that did not converge.
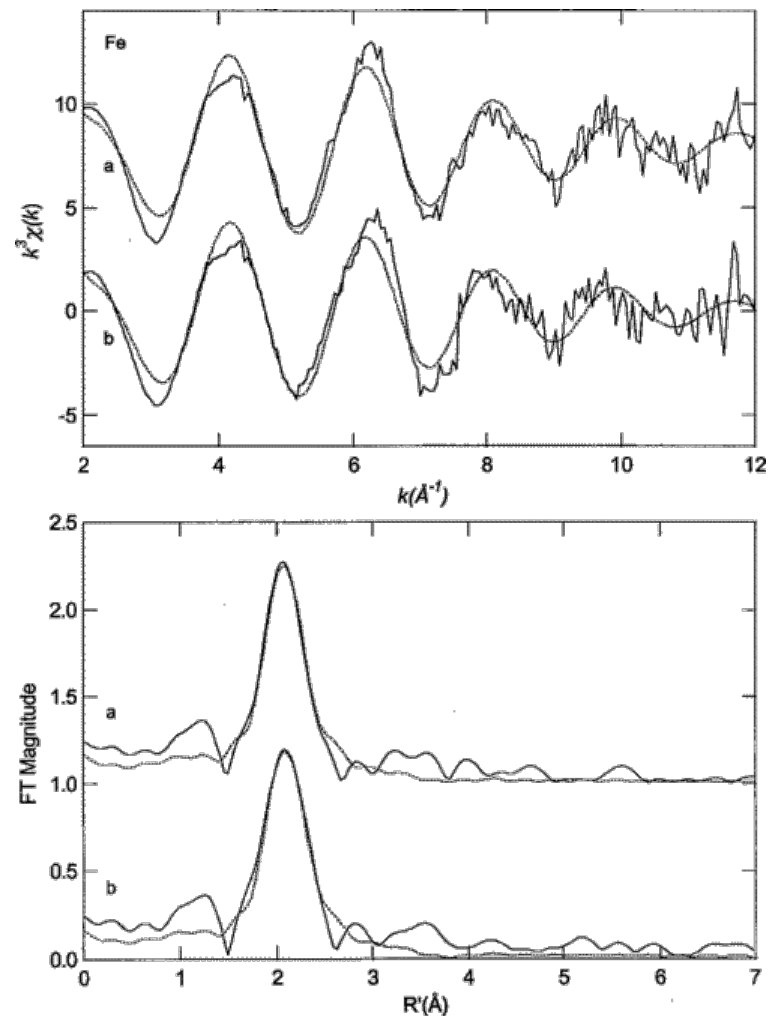

Figure $3 k^{3}$-weighted Fe EXAFS (top) and Fourier transforms (bottom, over $k=2-12 \AA^{-1}$ ) for (a) [Fe(II)Fe(II)(ECMetAP)] (solid) and the calculated spectra for Fe- ${ }_{5}$ (dotted; fit 7, Table 3) and (b) [Fe(II)_(EcMetAP)] (solid) and the calculated spectra for Fe-O ${ }_{5}$ (dotted; fit 2, Table 3).

Table 3: Curve-Fitting Results for Fe EcMetAP EXAFS ${ }^{a}$

\begin{tabular}{l|l|l|l|l|l|l|} 
fit & shell & $N_{\mathrm{s}}$ & $R_{\mathrm{as}}(\AA)$ & $\sigma_{\mathrm{as}}^{2}\left(\AA^{2}\right)$ & $\Delta E_{0}(\mathrm{eV})$ & $f^{\prime}$ \\
\hline
\end{tabular}




\begin{tabular}{|l|l|l|l|l|l|l|l|}
\hline$\left[\mathrm{Fe}(\mathrm{II}) \_(E c M e t A P)\right]$, & 1 & $\mathrm{Fe}-\mathrm{O}$ & 4 & 2.04 & 0.0080 & -0.98 & 0.108 \\
\hline $\mathrm{MF} 20 \mathrm{C}, 2-12 \AA^{-1}$, & 2 & $\mathrm{Fe}-\mathrm{O}$ & 5 & 2.03 & 0.0101 & -1.43 & 0.101 \\
\hline$\Delta k^{3} \chi=8.42$ & 3 & $\mathrm{Fe}-\mathrm{O}$ & 6 & 2.03 & 0.0122 & -1.81 & 0.101 \\
\hline & 4 & $\mathrm{Fe}-\mathrm{O}$ & 7 & 2.03 & 0.0144 & -2.14 & 0.106 \\
\hline$[\mathrm{Fe}(\mathrm{II}) \mathrm{Fe}(\mathrm{II})(E c \mathrm{MetAP})]$, & 6 & $\mathrm{Fe}-\mathrm{O}$ & 4 & 2.03 & 0.0074 & -2.21 & 0.094 \\
\hline $\mathrm{MF} 22 \mathrm{C}, 2-12 \AA^{-1}$, & 7 & $\mathrm{Fe}-\mathrm{O}$ & 5 & 2.03 & 0.0095 & -2.27 & 0.086 \\
\hline$\Delta k^{3} \chi=8.35$ & 8 & $\mathrm{Fe}-\mathrm{O}$ & 6 & 2.03 & 0.0116 & -2.47 & 0.087 \\
\hline & 9 & $\mathrm{Fe}-\mathrm{O}$ & 7 & 2.03 & 0.0137 & -2.65 & 0.093 \\
\hline$[\mathrm{Fe}(\mathrm{III}) \mathrm{Fe}(\mathrm{III})(E c \mathrm{MetAP})]$, & 10 & $\mathrm{Fe}-\mathrm{O}$ & 4 & 2.02 & 0.0071 & 0.08 & 0.083 \\
\hline $\mathrm{MF} 33 \mathrm{C}, 2-12 \AA^{-1}$, & 11 & $\mathrm{Fe}-\mathrm{O}$ & 5 & 2.02 & 0.0091 & -0.44 & 0.074 \\
\hline$\Delta k^{3} \chi=11.37$ & 12 & $\mathrm{Fe}-\mathrm{O}$ & 6 & 2.01 & 0.0110 & -0.92 & 0.072 \\
\hline & 13 & $\mathrm{Fe}-\mathrm{O}$ & 7 & 2.01 & 0.0129 & -1.33 & 0.074 \\
\hline
\end{tabular}

${ }^{a}$ See footnotes to Table 2.

The observed Fe(II) bond distances are in agreement with X-ray crystallographic data for the Co(II)loaded EcMetAP (16) and are also similar to those derived from fits of Co(II)-loaded EcMetAP. Since Fe(II)loaded EcMetAP is colorless, air sensitive, and EPR silent, no structural information has been reported for the catalytically competent [Fe(II)_(EcMetAP)] enzyme. Therefore, the EXAFS data of [Fe(II)_(EcMetAP)] and [Fe(II)Fe(II)(EcMetAP)] provide the first structural glimpse of the Fe(II) active site of EcMetAP and reveal that the first Fe(II) ion likely resides in a penta- or hexacoordinate geometry made up of oxygen or nitrogen donor ligands.

The lack of M-M FT peaks in the second shell of both Fe(II)- and Co(II)-loaded EcMetAP is consistent with the recently reported metal binding constants. The first metal binding event for $\mathrm{Co}(\mathrm{II})$ - and $\mathrm{Fe}(\mathrm{II})-$ substituted EcMetAP exhibited $K_{d}$ values of 300 and $200 \pm 200 \mathrm{nM}$, respectively (17). In addition, it was shown that the binding of excess metal ions ( $<50$ equiv) resulted in the loss of $\sim 50 \%$ of the catalytic activity. The second metal binding event for Co(II) EcMetAP was shown to have a $K_{d}$ value of $2.5 \pm 0.5 \mathrm{mM}$ (17). Therefore, under the conditions in which these EXAFS samples used in this study were prepared ( $1 \mathrm{mM}$ EcMetAP plus 1 or 2 equiv of divalent metal ion), one would not expect the second metal binding site to be occupied, consistent with the EXAFS data.

The lack of a second-shell metal ion scatterer is also consistent with the reported EPR signal for [Co(II)Co(II)(EcMetAP)]. The EPR spectra of both [Co(II)_(EcMetAP)] and [Co(II)Co(II)(EcMetAP)] are broad, featureless, and indistinguishable in form, suggesting an unconstrained ligand field. The observed EPR signal for [Co(II)_(EcMetAP)] integrated to one Co(II) ion per MetAP enzyme, and this signal doubled in intensity upon the addition of a second equivalent of Co(II). Moreover, the observed EPR signals followed Curie law over the temperature range 4-60 $\mathrm{K}$ at nonsaturating microwave powers (17). These data suggest that the $\mathrm{Co}(\mathrm{II})$ ions in [Co(II)Co(II)(EcMetAP)] exhibit no detectable spin-spin interaction, consistent with lack of a Co-Co active site. In support of these data, no integer spin signal could be detected in the parallel mode for EcMetAP at pH 7.5 (17). These data clearly indicate that no M-M interaction exists in either the mono- or dimetal Co(II) and Fe(II) EXAFS samples. Therefore, a dinuclear center is not formed upon addition of 1 or 2 equiv of either $\mathrm{Co}$ (II) or Fe(II) to ECMetAP at enzyme concentrations of $1 \mathrm{mM}$, which is clearly higher than in vivo MetAP concentrations. Similarly, the two Fe(III) ions in Fe(III)-loaded EcMetAP do not exhibit any significant spin-spin interaction on the basis of EPR spectroscopic studies, similar to the two Co(II) ions in Co(II)-substituted MetAP, further indicating that a dinuclear active site does not exist. These data are also consistent with EXAFS spectra of [Co(III)Co(III)(EcMetAP)] and [Fe(III)Fe(III)(EcMetAP)] which show no M-M interaction (Figure 4; Tables 2 and 3). 

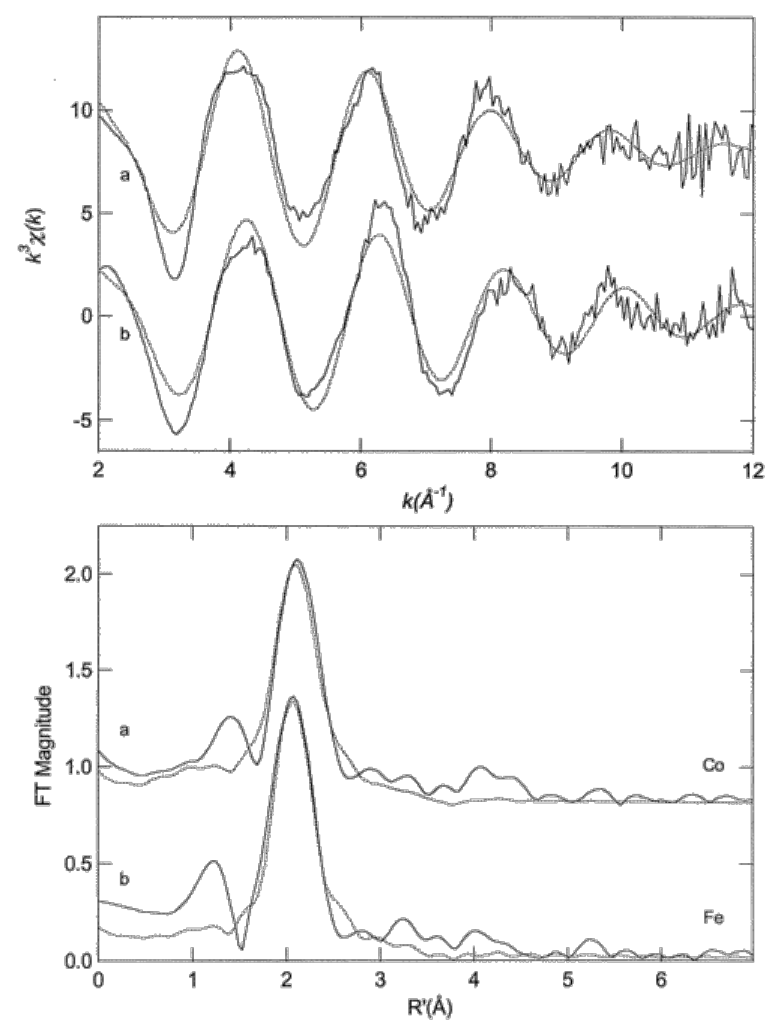

Figure $4 k^{3}$-weighted EXAFS (top) and Fourier transforms (bottom, over $k=2-12 \AA^{-1}$ ) for (a)

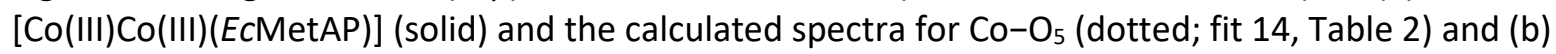
[Fe(III)Fe(III)(EcMetAP)] and the calculated spectra for $\mathrm{Fe}^{-\mathrm{O}_{5}}$ (dotted; fit 11, Table 3).

The range of temperatures over which the EPR signals from Co(II)-loaded EcMetAP were detectable can be compared with the temperature range of the detectable EPR signal from the Co(II)-loaded aminopeptidase from Aeromonas proteolytica ([Co(II)Co(II)(AAP)]) $(28,29)$. The two cobalt ions in [Co(II)Co(II)(AAP)] were shown to be spin-coupled, providing a spin-spin relaxation pathway that results in the spectrum of [Co(II)Co(II)(AAP)] obeying $1 / T$ dependence over only a narrow temperature range (9-15 $\mathrm{K}$ ). This electronic communication is likely mechanistically important for [Co(II)Co(II)(AAP)] in that a pathway for the modulation of the Lewis acidity of one metal ion by the other is present. Moreover, spin-spin interactions also reveal structural motifs such as $\mu-\mathrm{OH}(\mathrm{H})$ ligands. Since the observed EPR signal of [Co(II)Co(II)(ECMetAP)] was detectable at temperatures up to $60 \mathrm{~K}$ and the signal intensity was found to be inversely proportional to the absolute temperature, following Curie law dependence at nonsaturating microwave powers, one can then speculate that the proposed bridging water molecule observed in the X-ray crystal structure of EcMetAP is incapable of mediating detectable spin-spin coupling, presumably because the second metal ion does not exist in the active site in EPR-analyzed samples.

There is precedent for metallohydrolases that have crystallographically characterized dinuclear active sites to exhibit catalytic activity with only one metal ion bound. For instance, AAP, which has been crystallographically characterized, as well as the aminopeptidase from porcine kidney have long been known to be catalytically active with only one divalent metal ion present (31-34). For EcMetAP, the addition of up to 200 equiv of either $\mathrm{Co}$ (II) or Fe(II) resulted in a decrease in the catalytic activity, similar to the metal binding properties of the type I MetAP from S. cerevisiae but different from those of AAP and porcine kidney (31-35). These data suggest that the binding of a second metal ion to MetAP's is actually inhibitory, which would imply that the second metal ion does not have a catalytic role. Inhibition of catalytic activity by excess divalent metal ions has also been observed for other mononuclear metalloenzymes such as carboxypeptidase Taq when overexpressed in $E$. coli (36), bovine carboxypeptidase A $(37,38)$, and thermolysin (39). Inhibition of carboxypeptidase A was 
attributed to excess metal ion binding to an amino acid residue in the vicinity of the metallo active site that was involved in catalysis (37). In addition, the authors proposed that a bridging water/hydroxide, inserted between the two metal ions, enhanced the formation of a dinuclear site. This proposal was corroborated by X-ray crystallography where the structures of carboxypeptidase $A$, as well as thermolysin in the presence of excess metal ion, revealed two coordinated metal ions forming a ( $\mu$-hydroxo)dizinc(II) core with a Zn-Zn distance of 3.48 and $3.2 \AA$, respectively (39-41). Therefore, the observation that the addition of excess metal ions to ECMetAP inhibited enzymatic activity suggests that the inhibition is likely due to the occupation of a noncatalytically relevant metal binding site, similar to carboxypeptidase $A$.
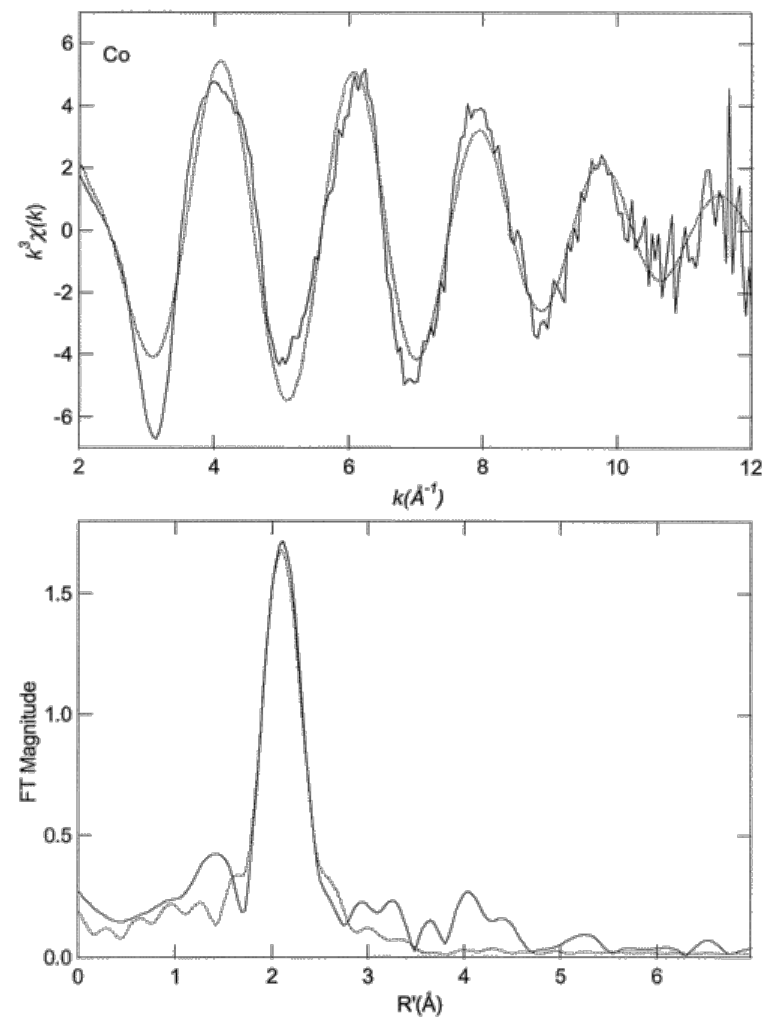

Figure $5 k^{3}$-weighted Co EXAFS (top) and Fourier transforms (bottom, over $k=2-12 \AA^{-1}$ ) for [Co(II)Co(II)(ECMetAP)] plus fumagillin (solid) and the calculated spectra for $\mathrm{Co}^{-} \mathrm{O}_{6}$ (dotted; fit 3, Table 4).

An important class of MetAP inhibitors is based on natural products of fungal origin, namely, fumagillin and ovalicin. Ovalicin and a synthetic analogue of fumagillin (AGM-1470) have been demonstrated to preferentially inhibit endothelial cell growth in tumor vasculature in vivo (42). On the basis of fumagillin-specific affinity reagents and mass spectroscopic studies on MetAP-fumagillin complexes, MetAP's were identified as the specific target of fumagillins $(10,11)$. The mode of inhibition was shown to be via the formation of a covalent bond between a conserved histidine residue in MetAP's and an epoxide carbon moiety on fumagillin $(10-12,43)$. Confirmation that fumagillin reacts with the type I MetAP from E. coli comes from mass spectrometric and Nterminal sequence analysis, which indicated that fumagillin covalently binds to an active site histidine residue (His79) that is not a ligand at the dinuclear active site cluster (12). To determine the interaction between the active site $\mathrm{Co}$ (II) ion of EcMetAP and the antiangiogenesis drug fumagillin, the EXAFS spectrum of [Co(II)Co(II)(EcMetAP)] was recorded after reaction with fumagillin. That fumagillin was covalently bound to a divalent metal ion loaded EcMetAP was verified by matrix-assisted laser desorption ionization time-of-flight (MALDI-TOF) spectrometric analysis, which revealed a mass shift of $451 \mathrm{Da}$, in excellent agreement with the mass of fumagillin (458 Da). 


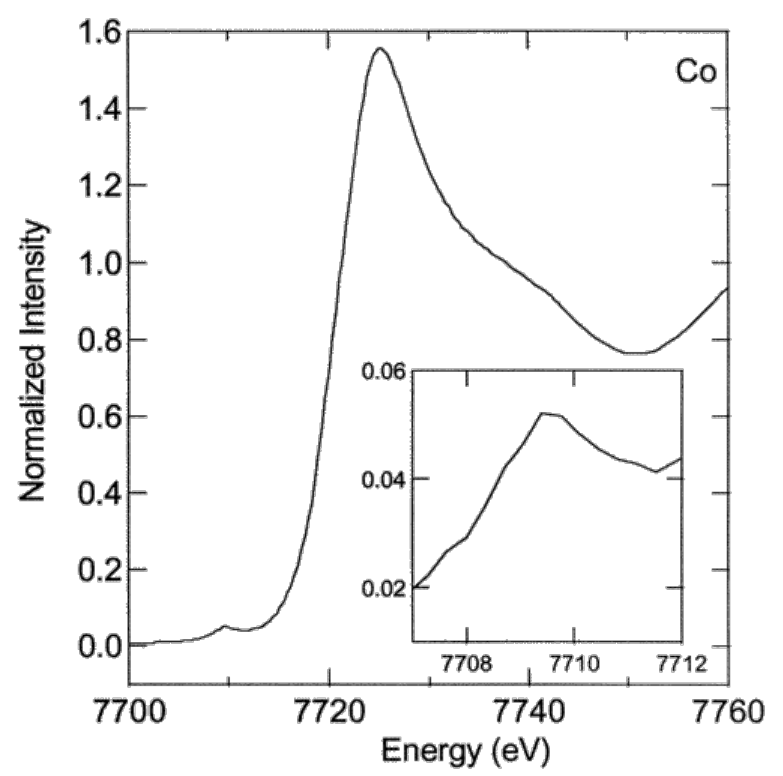

Figure $6 \mathrm{X}$-ray absorption K-edge spectra for [Co(II)Co(II)(EcMetAP)] plus fumagillin. In the inset, the preedge $1 \mathrm{~s}$ $\rightarrow 3 \mathrm{~d}$ transition is expanded.

Interestingly, but perhaps not surprisingly, no significant change in the XAS data for [Co(II)Co(II)(ECMetAP)] in the presence of fumagillin was observed (Figure 5). The $1 \mathrm{~s} \rightarrow 3 \mathrm{~d}$ preedge transition observed for [Co(II)Co(II)(EcMetAP)]-fumagillin occurs at $7709 \mathrm{eV}$ with a peak intensity of $0.127 \mathrm{eV}$ suggesting five- or sixcoordinate Co(II) sites (Figure 6) $(25,26)$. Excellent single-shell fits of the EXAFS spectrum of [Co(II)Co(II)(EcMetAP)]-fumagillin were obtained with 5 or 6 N/O scatterers at $2.05 \AA$, based on Debye-Waller factors. The residuals of the fits ( $f^{\prime}$ for fits 2 and 3; Table 4) were similar to those observed for [Co(II)Co(II)(EcMetAP)] without added fumagillin. Fits that include either a Co-Co interaction or the multiplescattering contributions from outer-shell atoms of a histidine ligand resulted in unreasonably high Debye-Waller factors (fits 5 and 6; Table 4). These data suggest that a dinuclear $\mathrm{Co}$ (II) site does not exist in [Co(II)Co(II)(EcMetAP)]-fumagillin, contrary to the published X-ray crystal structures for the MetAP from $\mathrm{H}$. sapiens (13). These data strongly suggest that, upon fumagillin binding, there is little, if any, change in the coordination sphere of the average Co(II) site.

Table 4: Curve-Fitting Results for [CoCo(EcMetAP)] + Fumagillin EXAFS ${ }^{a}$

\begin{tabular}{|l|l|l|l|l|l|l|l|}
\hline & fit & shell & $N_{\mathrm{s}}$ & $R_{\text {as }}(\AA)$ & $\sigma_{\text {as }}{ }^{2}\left(\AA^{2}\right)$ & $\Delta E_{0}(\mathrm{eV})$ & $f^{\prime}$ \\
\hline$[\mathrm{Co}(\mathrm{II}) \mathrm{Co}(\mathrm{II})(\mathrm{EcMetAP})]+$ fum, & 1 & Co-O & 4 & 2.06 & 0.0048 & -0.53 & 0.095 \\
\hline $\mathrm{MC2}$ FA, 2-12 $\AA^{-1}$, & 2 & Co-O & 5 & 2.05 & 0.0064 & -0.59 & 0.084 \\
\hline$\Delta k^{3} \chi=11.87$ & 3 & Co-O & 6 & 2.05 & 0.0080 & -0.84 & 0.079 \\
\hline & 4 & Co-O & 7 & 2.05 & 0.0096 & -1.02 & 0.080 \\
\hline & 5 & Co-(O,N) & 6 & 2.06 & 0.0080 & -0.76 & 0.077 \\
\hline & & Co-C & 1 & 2.88 & 0.0143 & & \\
\hline & & Co-C & 1 & {$[3.00]$} & {$[0.0148]$} & & \\
\hline & & Co-C & 1 & {$[3.97]$} & {$[0.0196]$} & & \\
\hline & & Co-N & 1 & {$[4.04]$} & {$[0.0200]$} & & \\
\hline & 6 & Co-O & 6 & 2.06 & 0.0080 & -0.83 & 0.078 \\
\hline & & Co-Co & 1 & 3.04 & 0.0196 & & \\
\hline
\end{tabular}

${ }^{a}$ See footnotes to Table 2.

Comparison of the EXAFS spectroscopic results for [Co(II)Co(II)(EcMetAP)]-fumagillin with the recent $1.8 \AA \AA$ X-ray crystal structure of the type II MetAP from $\mathrm{H}$. sapiens complexed with fumagillin (13) reveals striking similarities 
and differences. In the X-ray structure, the epoxide-bearing side chain of fumagillin occupies the putative substrate binding pocket of HsMetAP. The long unsaturated side chain is analogous to the $\mathrm{COOH}$-terminal peptide chain in the X-ray structure of a substrate analogue inhibited form of EcMetAP (15). The crystallographic results also verify that a covalent bond is formed between the reactive ring epoxide of fumagillin and His231 in the active site of the type II MetAP. The oxygen atom liberated from the breaking of the epoxide bond is $3.28 \AA$ away from Co1, the Co(II) ion bound by His331, Glu364, and the two bridging carboxylate residues, Asp262 and Glu459. This alkoxide oxygen atom was suggested to be directly coordinated to Co. The EXAFS results presented herein clearly indicate that the alkoxide oxygen atom of fumagillin is not an additional ligand to the Co(II) ion bound in the active site of EcMetAP, contrary to the suggestion by Liu et al. (13). Closer inspection of the X-ray crystal structure of HsMetAP complexed by fumagillin indicates that the approximate location of the alkoxide oxygen of fumagillin is where a water molecule resided at $>3 \AA$ from the Co(II) ion in the uncomplexed structure. Therefore, we propose that the oxygen atom liberated upon the addition of fumagillin to EcMetAP displaces the water molecule that bridges between His178 and the water molecule bridging the two Co(II) ions in the X-ray structure of native EcMetAP (Figure 7). Thus, fumagillin does not provide a ligand to the metal ion in the EcMetAP active site. Since fumagillin has two reactive epoxide moieties, it is quite cytotoxic, probably due to alkylation of other biomolecules within the cell. Therefore, understanding the molecular mechanism of the MetAP-catalyzed cleavage of $\mathrm{N}$-terminal methionine residues as well as the binding mode of known antiangiogenesis drugs will facilitate the rational design of new, more potent MetAP inhibitors with improved in vivo stability, specificity, and lower cytotoxicity.

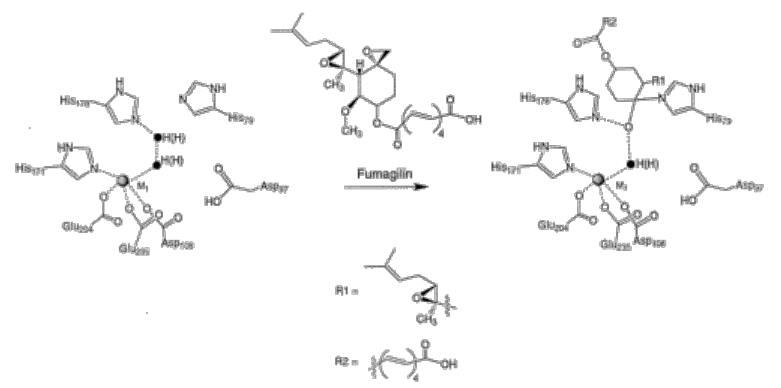

Figure 7 Proposed structure of the mono-Co(II) or mono-Fe(II) forms of EcMetAP in the presence of fumagillin.

\section{Acknowledgment}

The methionyl aminopeptidase from E. coli was purified from a stock culture kindly provided by Drs. Brian Matthews and W. Todd Lowther.

\section{References}

1 Bradshaw, R. A. (1989) Trends Biochem. Sci.14, 276-279.

2 Meinnel, T., Mechulam, Y., and Blanquet, S. (1993) Biochimie75, 1061-1075.

3 Bradshaw, R. A., Brickey, W. W., and Walker, K. W. (1998) Trends Biochem. Sci.23, 263-267.

4 Arfin, S. M., and Bradshaw, R. A. (1988) Biochemistry27, 7979-7984.

5 Hirel, P.-H., Schmitter, J.-M., Dessen, P., Fayat, G., and Blanquet, S. (1989) Proc. Natl. Acad. Sci. U.S.A.86, 8247-8251.

6 Chang, S.-Y. P., McGary, E. C., and Chang, S. (1989) J. Bacteriol.171, 4071-4072.

7 Miller, C. G., Kukral, A. M., Miller, J. L., and Movva, N. R. (1989) J. Bacteriol.171, 5215-5217.

8 Li, X., and Chang, Y.-H. (1995) Proc. Natl. Acad. Sci. U.S.A.92, 12357-12361.

9 Taunton, J. (1997) Chem. Biol.4, 493-496. 
10 Griffith, E. C., Su, Z., Turk, B. E., Chen, S., Chang, Y.-H., Wu, Z., Biemann, K., and Liu, J. O. (1997) Chem. Biol.4, 461-471.

11 Sin, N., Meng, L., Wang, M. Q., Wen, J. J., Bornmann, W. G., and Crews, C. M. (1997) Proc. Natl. Acad. Sci. U.S.A.94, 6099-6103.

12 Lowther, W. T., McMillen, D. A., Orville, A. M., and Matthews, B. W. (1998) Proc. Natl. Acad. Sci. U.S.A.95, 12153-12157.

13 Liu, S., Widom, J., Kemp, C. W., Crews, C. M., and Clardy, J. (1998) Science282, 1324-1327.

14 Tahirov, T. H., Oki, H., Tsukihara, T., Ogasahara, K., Yutani, K., Ogata, K., Izu, Y., Tsunasawa, S., and Kato, I. (1998) J. Mol. Biol.284, 101-124.

15 Lowther, W. T., Orville, A. M., Madden, D. T., Lim, S., Rich, D. H., and Matthews, B. W. (1999) Biochemistry38, 7678-7688.

16 Roderick, S. L., and Matthews, B. W. (1993) Biochemistry32, 3907-3912.

17 D'souza, V. M., Bennett, B., and Holz, R. C. (2000) Biochemistry39, 3817-3826.

18 D'souza, V. M., and Holz, R. C. (1999) Biochemistry38, 11079-11085.

19 Scott, R. A. (1985) Methods Enzymol.117, 414-458.

20 Teo, B. K. (1981) EXAFS Spectroscopy. Techniques and Applications, Plenum Press, New York.

21 Cosper, N. J., Stalhandske, C. M. V., Saari, R. E., Hausinger, R. P., and Scott, R. A. (1999) J. Biol. Inorg. Chem.4, 122-129.

22 Zabinsky, S. I., Rehr, J. J., Ankudinov, A., Albers, R. C., and J., E. M. (1995) Phys. Rev. B52, 2995-3009.

23 Jansen, J. C., Verhage, M., and van Konigsveld, H. (1982) Cryst. Struct. Commun.11, 305.

24 Strandberg, R., and Lundberg, B. K. S. (1900) Acta Chem. Scand.25, 1767-1774.

25 Wirt, M. D., Sagi, I., Chen, E., Frisbis, S. M., Lee, R., and Chance, M. R. (1991) J. Am. Chem. Soc.113, 299-5304.

26 Zhang, J. H., Kurtz, D. M., Maroney, M. J., and Whitehead, J. P. (1991) Inorg. Chem.30, 1359-1366.

27 Lowther, T. W., Zhang, Y., Sampson, P. B., Honek, J. F., and Matthews, B. W. (1999) Biochemistry 38, 14810-14819.

28 Bennett, B., and Holz, R. C. (1997) J. Am. Chem. Soc.119, 1923-1933.

29 Bennett, B., and Holz, R. C. (1997) Biochemistry36, 9837-9846.

30 Randall, C. R., Shu, L., Chiou, Y.-M., Hagen, K. S., Ito, M., Kitajima, N., Lachicotte, R. J., Zang, Y., and Que, L., Jr. (1995) Biochemistry34, 1036-1039.

31 Prescott, J. M., and Wilkes, S. H. (1976) Methods Enzymol.45B, 530-543.

32 Prescott, J. M., Wagner, F. W., Holmquist, B., and Vallee, B. L. (1983) Biochem. Biophys. Res. Commun.114, 646-652.

33 Prescott, J. M., Wagner, F. W., Holmquist, B., and Vallee, B. L. (1985) Biochemistry24, 5350-5356.

34 Lehky, P., Lisowski, J., Wolf, D. P., Wacker, H., and Stein, E. A. (1973) Biochim. Biophys. Acta321, 274-281.

35 Walker, K. W., and Bradshaw, R. A. (1998) Protein Sci.7, 2684-2687.

36 Lee, S. H., Taguchi, H., Yoshimura, E., Minagawa, E., Kaminogawa, S., Ohta, T., and Matsuzawa, H.

(1994) Biosci., Biotechnol., Biochem.58, 1490-1495.

37 Larsen, K. S., and Auld, D. S. (1989) Biochemistry28, 9620-9625.

38 Larsen, K. S., and Auld, D. S. (1991) Biochemistry30, 2613-2618.

39 Holland, D. R., Hausrath, A. C., Juers, D., and Matthews, B. W. (1995) Protein Sci.4, 1955-1965.

40 Gomez-Ortiz, M., Gomis-Ruth, F. X., Huber, R., and Aviles, F. X. (1997) FEBS Lett.400, 336-340.

41 Bukrinsky, J. T., Bjerrum, M. J., and Kadziola, A. (1998) Biochemistry37, 16555-16564.

42 Yamamoto, T., Sudo, K., and Fujita, T. (1994) Anticancer Res14.

43 Turk, B. E., Su, Z., and Liu, J. O. (1998) Bioorg. Med. Chem.6, 1163-1169.

1 Abbreviations: CHES, 2-( $N$-cyclohexylamino)ethanesulfonic acid; EPR, electron paramagnetic resonance; EXAFS, extended X-ray absorption fine structure; HEPES, $N$-(2-hydroxyethyl)piperazine- $N{ }^{\prime}-2$ - 
ethanesulfonic acid; ICP-AES, inductively coupled plasma atomic emission spectroscopy; NMR, nuclear magnetic resonance; MetAP, methionyl aminopeptidase; MOPS, 3-(N-morpholino)propanesulfonic acid; XAS, X-ray absorption spectroscopy. 